(C) 1981. The Genetical Society of Great Britain

\title{
BIASED SEX RATIOS IN LABORATORY STRAINS OF GUPPIES, POECILIA RETICULATA
}

\author{
JAMES A. FARR* \\ Institut für Biologie, Gesellschaft für Strahlen- und Umweltforschung, \\ D-8042 Neuherberg bei München, Federal Republic of Germany
}

Received 2.iv.81

\begin{abstract}
SUMMARY
Older laboratory strains of guppies, Poecilia reticulata, exhibit female-biased sex ratios. The results of interstrain crosses and crosses involving exceptional $Y Y$ males showed that the sex ratio phenomenon is determined primarily by $Y$-linked genes which result either in decreased production of $Y$-bearing sperm, or in lowered ability of $Y$-bearing sperm to compete with $X$-bearing sperm for ova. Inbreeding and local mate competition cannot account for the evolution of the sex ratio deviations. It is suggested that the sex ratio effect is caused either by pleiotropic effects of $Y$-linked genes increasing the ability of males to compete for females, or by a genetic deterioration of the $Y$-chromosomes through accumulation of deleterious alleles. The latter suggestion is supported by the theoretical models of Nei (1970) and Charlesworth (1978) on the evolution of inert $Y$-chromosomes.
\end{abstract}

\section{INTRODUCTION}

Sex ratio theory has had two major turning points. First, Fisher (1930) explained why sex ratios tend to be $1: 1$. Then Hamilton (1967) outlined conditions under which sex ratios should deviate from unity. He considered mechanisms of sex-linked drive and introduced the important concept of local mate competition and its probable effect on sex ratios. With the renewed interest in sex ratios stimulated by Hamilton's seminal work, it is important to examine cases of extraordinary sex ratios, both their underlying genetic mechanisms and their possible adaptive significance.

In the following report $I$ describe an instance of biased sex ratios in laboratory strains of the live-bearing teleost Poecilia (=Lebistes) reticulata, the common guppy. I encountered the problem in a study of intermale competition and reproductive success (Farr, 1980); it was of ten impossible to determine which of two or more competing genetically-marked males had inseminated a female because too few males were in the resulting broods. Through analysis of brood records from this experiment and from subsequent work on the inheritance of quantitative patterns of sexual behaviour (Farr, in prep.), I was able to determine how female-biased sex ratios are inherited and to speculate on their biological significance.

Sex determination in guppies is basically by an $X Y$ system, with heterogametic males (Schmidt, 1920; Winge, 1922). The sex-determining genes are contained on non-pairing segments of otherwise homologous chromosomes, as seen in the crossing-over patterns of genes for male secondary sexual colouration lying adjacent to the non-pairing segments (Winge, 1923; Dzwillo, 1959). Autosomal genes can also influence sex

* Present address: Department of Biological Science, Florida State University, Tallahassee, Florida 32306, U.S.A. 
determination. Although the major sex-determining genes are on the sex chromosomes, an accumulation of autosomal sex-determining genes can result in sex reversals, i.e., $X Y$ females and $X X$ males (Winge, 1930, 1934). $Y Y$ males heterozygotic for $Y$-linked colour patterns are viable and fertile (Winge, 1934; Winge and Ditlevsen, 1947; the present study), but a recessive lethal prevents production of $Y Y$ homozygotes (Winge and Ditlevsen, 1938; Haskins et al., 1970). The $Y$-chromosome is not inert. A majority of male secondary sexual colour patterns are $Y$-linked (Haskins et al., 1961, and reviews by Winge and Ditlevsen, 1947; Dzwillo, 1959; Yamamoto, 1975), and level of male sexual activity is also apparently primarily $Y$-linked (Farr, in prep.).

The data presented below allow one to answer the following questions:

(1) Is the sex ratio bias determined by $X-, Y$-, or autosomally-linked genes?

(2) Is there differential production of $X X$ and $X Y$ genotypes, or is there a high incidence of $X Y$ sex reversals?

(3) Is there a lethal gene resulting in the death of $X Y$ (male) embryos, or are fewer $Y$-bearing sperm being produced or achieving fertilization?

(4) Do females influence the sex ratios of their broods in accordance with the model of Trivers and Willard (1973)? Do older, less viable females tend to produce more females in later broods because their sons may reflect the reduced viability and not be able to compete with healthier males for females?

Once these questions are answered, the laboratory conditions under which the fish are maintained are examined to determine the possible evolutionary cause of the observed sex ratio biases.

\section{MAterials AND METHOdS}

Seven strains of guppies are included in this study. They are not inbred in the sense that they have been maintained by repeated sib mating, but they have been maintained in small laboratory populations for many years and are probably nearly isogenic. The male secondary sexual colouration characteristic of each strain is at least partially $Y$-linked. A full description of the strains with original literature can be found in Farr (1980). The names of the strains with the abbreviations used throughout the paper are:

Maculatus (Ma)

Pauper $(\mathrm{Pa})$

Cream/Armatus (Cr/Ar)

Istanbul (Ist)

Maculatus/Gold (Ma/gg)

Nigrocaudatus/Filigran (Ni/Fil or Fil)

Blau Iridescens (Bl/Ir)

To determine the base sex ratio of each strain, I removed a minimum of 50 young from the stock aquaria and kept them in groups of five in 101 aquaria until they reached maturity. Sex cannot be determined until sexual maturity is reached; males develop their secondary sexual colouration and a gonopodium, the anal fin modified into a copulatory organ. Age of the young at the time they were removed from the stock aquaria was unknown, but I attempted to take the smallest possible. Average age was probably 
less than one week. I staggered sampling of each strain over at least four weeks to reduce the probability that all young were from one or a few aberrant broods.

For a detailed account of methods used in obtaining virgin females for interstrain crosses and of experimental conditions and techniques, the reader is referred to Farr (1980). The data in table 2 resulted from experiments in which males of two strains competed for females of a third strain. Paternity was determined by examining the $Y$-linked colouration of male offspring. There is thus a danger of undetected multiple paternity. All subsequent data are from crosses in which there was only one possible father.

Sex ratios are expressed as males:females throughout the paper. All ratios were tested for significant deviations from unity by means of a normal approximation of binomial probabilities with $p=0 \cdot 5$, corrected for continuity (Snedecor and Cochran, 1967). Comparisons of two ratios were performed by $\chi^{2}$ test, of three or more ratios by Bartholomew's (1959) test of homogeneity for ordered alternatives.

\section{REsults}

The sex ratios of the seven strains are shown in table 1 . Three strains, $\mathrm{Ma}, \mathrm{Pa}$, and $\mathrm{Cr} / \mathrm{Ar}$, henceforth designated Sex Ratio (SR) strains, exhibited sex ratios significantly less than unity; the other four were Normal. There is a significant correlation between age and sex ratio of the strains. Ma and $\mathrm{Pa}$ are the oldest, being described in 1920 (Schmidt) and 1927 (Winge), respectively, and have the most biased sex ratios. $\mathrm{Bl} / \mathrm{Ir}$ and $\mathrm{Ni} /$ Fil were first described in 1959 by Dzwillo and have the most normal sex ratios. The others can be considered intermediate in age. Ist was also described by Dzwillo (1959), but the males had already been selected for elongated caudal fins, and the strain is thus probably older than either $\mathrm{Bl} / \mathrm{Ir}$ or Ni/Fil. $\mathrm{Ma} / \mathrm{gg}$ and $\mathrm{Cr} / \mathrm{Ar}$ have $Y$-linked colouration described by Schmidt (1920) and Winge (1927), respectively, but were later outcrossed to incorporate

\section{TABLE 1}

The sex ratios $(M: F)$ of seven inbred strains of guppies, Poecilia reticulata

$\begin{array}{lc}\mathrm{Ma} & 18: 42^{* *} \\ & (0 \cdot 429) \\ \mathrm{Pa} & 27: 48^{*} \\ & (0 \cdot 563) \\ \mathrm{Cr} / \mathrm{Ar} & 29: 46^{*} \\ & (0 \cdot 630) \\ \mathrm{Ist} & 32: 43 \\ & (0 \cdot 744) \\ \mathrm{Ma} / \mathrm{gg} & 22: 28 \\ & (0 \cdot 786) \\ \mathrm{Ni} / \mathrm{Fil} & 26: 24 \\ & (1 \cdot 083) \\ \mathrm{BI} / \mathrm{Ir} & 26: 24 \\ & (1 \cdot 083)\end{array}$

** Significantly less than unity, $\alpha<0 \cdot 01$.

* Significantly less than unity, $\alpha<0 \cdot 05$. 
TABLE 2

Sex ratios resulting from interstrain crosses with males and females from Sex Ratio and Normal strains. Values in parentheses are number of crosses from which data were taken, followed by total number of offspring which died before sex could be determined

\begin{tabular}{lll} 
& \multicolumn{1}{c}{$\begin{array}{c}\text { Sex Ratio } \\
\text { Females }\end{array}$} & \multicolumn{1}{c}{$\begin{array}{c}\text { Normal } \\
\text { Females }\end{array}$} \\
Sex Ratio & $149: 248^{* * *}$ & $155: 220^{* * *}$ \\
Males & $0 \cdot 601$ & $0 \cdot 705$ \\
& $(49,7)$ & $(45,19)$ \\
Normal & $170: 206^{*}$ & $119: 143$ \\
Males & $0 \cdot 825$ & $0 \cdot 832$ \\
& $(56,38)$ & $(42,19)$
\end{tabular}

*** Significantly less than unity, $\alpha<0.001$.

* Significantly less than unity, $\alpha<0.05$.

autosomal recessive genes for overall body colouration. The combined sex ratios for each of the three groups of strains, ranked from oldest to most recent, are $0.500(\mathrm{Ma}$ and $\mathrm{Pa}), 0.709(\mathrm{Cr} / \mathrm{Ar}$, Ist, and $\mathrm{Ma} / \mathrm{gg})$, and 1.083 (Bl/Ir and Ni/Fil). Bartholomew's (1959) test for ordered alternatives shows a significant increase in sex ratio with decreasing strain age $\left(\chi^{2}=8 \cdot 25\right.$, $\left.-\rho_{12}=0.367, \alpha<0.01\right)$.

Table 2 combines data for all interstrain crosses involving SR and Normal strains. Crosses with SR males as fathers resulted in sex ratios highly significantly less than unity, regardless of the strains from which the females were taken. If one assumes that all offspring which died before their sex could be determined were males, the sex ratios remain significantly biased. Normal males crossed with SR females produced marginally significantly biased sex ratios $(\alpha<0 \cdot 05$, one-tailed test, $\alpha>0 \cdot 05$, two-tailed test). If all offspring which died before attaining sexual maturity were males, the sex ratio is not different from unity. The sex ratio resulting from crosses between Normal males and Normal females was not significantly biased.

A three-dimensional contingency table analysis (Sokal and Rohlf, 1969) was performed on the data in table 2 to determine the contributions of maternal and paternal genotypes to the sex ratio. The sex ratio was significantly dependent on paternal genotype $(G=5.020, \mathrm{df}=1, \alpha<$ $0.025)$, but was independent of maternal genotype $(G=0.436$, df $=1$, $\alpha \gg 0.05)$. There was no significant interaction of parental genotypes on the sex ratio $(G=0.734, \mathrm{df}=1, \alpha \gg 0.05)$. It can be concluded from this analysis that biased sex ratios are determined primarily by the males.

The tendency for reduced sex ratios in broods from Normal males and SR females could result either from an additional slight, statistically undetectable contribution by the females to the sex ratio, or from the artificial division of the strains into rigidly defined groups with either normal or biased sex ratios. Increased sample sizes could have shown that some strains designated Normal could actually have female-biased sex ratios higher than those of the strains classified as SR.

Spontaneous sex reversals can occur in guppies. The above data could result from either a differential production of $X X$ and $X Y$ genotypes, or equal frequencies of $X X$ and $X Y$ individuals in which a proportion of $X Y$ individuals were phenotypically female. $X Y$ females do not typically 
express $Y$-linked colour patterns, but those with the $Y$-linked Ma pattern can be recognised by a black spot on the dorsal fin; no such females were found in any crosses involving Ma males ( $N=198$ females in 40 broods). However, the dorsal spot is often weak and may not appear until several weeks after the females are mature, so I paired 23 females from crosses with Ma fathers (the strain with the most biased sex ratio) with males exhibiting various other $Y$-linked colour patterns. If any of these females were $X Y^{\mathrm{Ma}}$, the resulting offspring should have shown a sex ratio of $3: 1$, with one-third of the males exhibiting the Ma pattern, one-third the pattern of the father, and one-third exhibiting both patterns ( $Y Y$ males). Only 20 females produced offspring, and all 20 were confirmed $X X$. In addition, in no interstrain cross $(N>200)$ did females produce male offspring exhibiting the $Y$-linked colouration of the maternal strain, as would be expected if some of the females were $X Y$. The sex ratio phenomenon is the result of differential production of $X X$ and $X Y$ genotypes, not of reversal of $X Y$ genotypes to females.

In all of the above interstrain crosses there were two possible fathers, one from each of two competing strains. Paternity was determined by examining the colouration of male offspring, and mixed broods (sired by two strains) were excluded. It is possible, however, particularly if one potential father was from an SR strain, that one sire was undetected. This would tend to distort the data in such a manner that some crosses would show biased sex ratios with Normal males as fathers, although Ma males were found in the greatest proportion of broods despite the sex ratio bias (Farr, 1980). Paternity could obviously not be determined in all-female broods.

To analyse the problem further, and to alleviate uncertainty as to paternity, a series of crosses with the strains Ma (an SR strain) and $\mathrm{Bl} / \mathrm{Ir}$ (a Normal strain) were performed. The cross of Ma males with $\mathrm{Bl} / \mathrm{Ir}$ females is designated $\mathrm{Ma}-\mathrm{F}_{1}$, the reciprocal cross as $\mathrm{Bl}-\mathrm{F}_{1}$. Males of each $F_{1}$ generation were backcrossed to females of both parental strains. The cross of $\mathrm{Ma}-\mathrm{F}_{1}$ males with Ma females is designated $\mathrm{MM}$, with $\mathrm{Bl} / \mathrm{Ir}$ females as $\mathrm{MB}$. The respective crosses with $\mathrm{Bl}-\mathrm{F}_{1}$ males are $\mathrm{BM}$ and $\mathrm{BB}$. Thus, the first letter refers to the $Y$-chromosome colour marker, the second to maternal strain. The sex ratios of the parental strains are taken from table 1. Table 3 lists the resulting sex ratios from each cross. All crosses in which the father carried the Ma $Y$-chromosome resulted in sex ratios significantly less than unity. All with the $\mathrm{Bl} / \mathrm{Ir} Y$-chromosome were not significantly different from unity.

A comparison of the various crosses allows determination of whether the sex ratio phenomenon is caused by genes on the $Y$-chromosome itself or by autosomal modifiers which interact epistatically with the Ma $Y$ chromosome. If there are autosomal modifiers with a strictly additive effect, the sex ratios should increase in the order Ma-parental $<\mathrm{MM}<\mathrm{Ma}-\mathrm{F}_{1}<$ $\mathrm{MB}$, because the $\mathrm{Ma}$ autosomal gene dosage decreases by 25 per cent increments from 100 per cent to 25 per cent. The actual sex ratios, 0.429 , $0 \cdot 636,0 \cdot 643$, and $0 \cdot 702$, respectively, do, in fact, follow the correct order. However, use of Bartholomew's (1959) test of homogeneity for ordered alternatives revealed that the successive increase was not significant $\left(\chi^{2}=\right.$ $4.37,-\rho_{12}=0.773,-\rho_{23}=0.181, \alpha>0.05$ ), so it can be concluded that there is no additive autosomal gene influence on the sex ratio. 
TABLE 3

A summary of the sex ratios of the strains $M a$ and $B l / I r$, their $F_{1}$ hybrids, and the four possible backcross combinations. $M a-F_{1}$ and $B l-F_{1}$ refer to crosses with $M a$ and $B l / I r$ males, respectively. The two-letter designations of the backcrosses refer first to the $F_{1}$ male, then the female strain to which he was backcrossed. $M B$ is the backcross of $M a-F_{1}$ males to Bl/Ir females, etc. The parental generation data are from table 1. N refers to the number of females from which data were taken

$\begin{array}{llll}\text { Ma: } & 18: 42^{* *} & \mathrm{Bl} / \mathrm{Ir}: & 26: 24 \\ & 0 \cdot 429 & & 1 \cdot 083 \\ \text { Ma-F }: & 45: 70^{*} & \mathrm{~B} 1-\mathrm{F}_{1}: & 57: 68 \\ & 0 \cdot 643 & & 0 \cdot 838 \\ & N=14 & & N=7 \\ \text { MM: } & 145 \cdot 228^{* * *} & \mathrm{BM}: & 152: 160 \\ & 0 \cdot 636 & & 0 \cdot 950 \\ \text { MB: } & N=16 & & N=14 \\ & 178: 235^{* *} & \mathrm{BB}: & 241: 224 \\ & 0 \cdot 702 & & 1 \cdot 076 \\ & N=15 & & N=16\end{array}$

\footnotetext{
*** Significantly less than unity, $\alpha<0 \cdot 001$

** Significantly less than unity, $\alpha<0 \cdot 01$.

* Significantly less than unity, $\alpha<0 \cdot 05$.
}

If the sex ratio effect were determined by one or more recessive autosomal alleles interacting with the $Y$-chromosome, one would expect a 1:1 sex ratio from any cross with an SR male and a Normal female, in this case $\mathrm{Ma}-\mathrm{F}_{1}$ and $\mathrm{MB}$. Both of these crosses resulted in biased sex ratios, so recessive autosomal genes can be excluded.

If one or more dominant genes operate epistatically with the $Y$-chromosome to produce the sex ratio distortion, one would expect $\mathrm{MB}$ backcrosses to have a higher sex ratio than MM backcrosses. All MM offspring have a full complement of $\mathrm{Ma}$ autosomes, whereas only one-half of one haploid genome in the MB offspring is from the original Ma strain. The two crosses did not differ with respect to sex ratio $\left(\chi^{2}=1 \cdot 45, \mathrm{df}=1, \alpha>0 \cdot 05\right)$, so there are no dominant autosomal genes interacting with the $Y$-chromosome.

A final series of crosses was performed. Four females with a black spot on the dorsal fin were discovered in an aquarium of virgins set aside from various strains and interstrain crosses for behavioural tests. Their origin in unknown, but it was suspected they might be sex-reversed $X Y^{\mathrm{Ma}}$ females (see above). Two were paired with $\mathrm{Pa}$ males (an SR strain) and two with Fil males (a Normal strain). The resulting offspring exhibited the expected 3:1 sex ratio, and one-third of the males exhibited both the Ma colour pattern and that of their father. As these patterns are all $Y$-linked, it was concluded that the original females were $X Y^{\mathrm{Ma}}$, and that one-third of the resulting males were $Y Y$.

The $Y Y$ males, six $Y^{\mathrm{Ma}} Y^{\mathrm{Pa}}$ and twelve $Y^{\mathrm{Ma}} Y^{\mathrm{Fil}}$, were paired with normal $X X$ females. Because $\mathrm{Ma}$ and $\mathrm{Pa}$ are both SR strains, and if the sex ratio effect is determined by the $Y$-chromosomes, one would expect those crosses with $Y^{\mathrm{Ma}} Y^{\mathrm{Pa}}$ males to produce $X Y^{\mathrm{Ma}}$ and $X Y^{\mathrm{Pa}}$ males in a ratio of $1: 1$. Those with $Y^{\mathrm{Ma}} Y^{\mathrm{Fil}}$ males should produce an excess of $X Y^{\mathrm{Fil}}$ males.

The crosses with $Y^{\mathrm{Ma}} Y^{\mathrm{Pa}}$ males produced 61 Ma males, $74 \mathrm{~Pa}$ males, and one female with a spotted dorsal fin. This female was crossed with 
another strain and was shown to be $X Y^{\mathrm{Ma}}$, so the final count is $62 X Y^{\mathrm{Ma}}$ individuals and $74 X Y^{\mathrm{Pa}}$ males, a ratio of 0.838 and not significantly different from unity.

Crosses involving $Y^{\mathrm{Ma}} Y^{\mathrm{Fil}}$ males produced 69 Ma males, 145 Fil males, and 33 females with a spotted dorsal fin. The females were crossed further, and the 29 which produced young proved to be $X Y^{\mathrm{Ma}}$ sex reversals. Thus, there were $102 X Y^{\mathrm{Ma}}$ individuals and $145 X Y^{\mathrm{Fil}}$ males. The ratio $102: 145$ $(=0.703)$ is significantly less than unity $\left(z_{c}=2.67, \alpha<0.01\right)$ as expected from the hypothesis that the sex ratio phenomenon is determined solely by the $Y$-chromosome.

There are three mechanisms whereby the $Y$-chromosome can affect the sex ratio. During meiosis, fewer $Y$-bearing sperm could be produced. If $X$ - and $Y$-bearing sperm are produced in equal numbers, $Y$-bearing sperm could be less effective in competing with $X$-bearing sperm for a female's ova. Or there is a reduced viability of $X Y$ zygotes resulting in differential survival of $X X$ and $X Y$ embryos. The first two possibilities will be discussed below. The third can be tested with the present data.

If the sex ratio effect is caused by a higher mortality of $X Y$ embryos, one would expect average brood size to be lower in those crosses resulting in female-biased sex ratios. Because there are age-fecundity, size-fecundity, and age-size correlations in the Poeciliidae (Krumholz, 1948; Affieck, 1960; Wu et al., 1974), I have outlined separately the average sizes of first, second, and third broods produced by females in the backcrosses involving the strains $\mathrm{Ma}$ and $\mathrm{Bl} / \mathrm{Ir}$ (table 4). Size of the females was not measured,

\section{TABLE 4}

Mean and standard error (SE) of the size of the nth broods produced by females in the backcrosses involving the strains $\mathrm{Ma}$ and $\mathrm{Bl} / \mathrm{Ir}$. N refers to the number of females from which data were taken. There were no significant differences in mean brood size between paternal genotypes within maternal genotypes

\begin{tabular}{|c|c|c|c|c|}
\hline Brood No. & MM & BM & MB & $\mathrm{BB}$ \\
\hline 1 & $\begin{array}{l}5 \cdot 00 \\
\mathrm{SE}=0 \cdot 77 \\
N=16\end{array}$ & $\begin{array}{l}6 \cdot 43 \\
\mathrm{SE}=181 \\
N=14\end{array}$ & $\begin{array}{l}6 \cdot 07 \\
\mathrm{SE}=1 \cdot 04 \\
N=15\end{array}$ & $\begin{array}{l}7 \cdot 25 \\
\mathrm{SE}=0 \cdot 95 \\
N=16\end{array}$ \\
\hline 2 & $\begin{array}{l}10 \cdot 07 \\
\mathrm{SE}=1 \cdot 12 \\
N=14\end{array}$ & $\begin{array}{l}8 \cdot 69 \\
\mathrm{SE}=0 \cdot 80 \\
N=13\end{array}$ & $\begin{array}{l}11 \cdot 71 \\
\mathrm{SE}=1 \cdot 84 \\
N=14\end{array}$ & $\begin{array}{l}10 \cdot 88 \\
\mathrm{SE}=1 \cdot 75 \\
N=16\end{array}$ \\
\hline 3 & $\begin{array}{l}12 \cdot 67 \\
\mathrm{SE}=1 \cdot 12 \\
N=12\end{array}$ & $\begin{array}{l}9 \cdot 91 \\
\mathrm{SE}=1 \cdot 51 \\
N=11\end{array}$ & $\begin{array}{l}13 \cdot 17 \\
\mathrm{SE}=1 \cdot 94 \\
N=12\end{array}$ & $\begin{array}{l}11 \cdot 67 \\
\mathrm{SE}=1 \cdot 74 \\
N=15\end{array}$ \\
\hline
\end{tabular}

but I attempted to hold within-strain size variation at a minimum when the females were first paired with males. If the sex ratio effect is caused by differential embryo survival, average brood size of $\mathrm{Ma}$ or $\mathrm{Bl} / \mathrm{Ir}$ females should be greater when they are crossed with $\mathrm{Bl}_{1} \mathrm{~F}_{1}$ males (backcrosses $\mathrm{BM}$ and $\mathrm{BB}$, respectively) than when crossed with $\mathrm{Ma}-\mathrm{F}_{1}$ males (backcrosses $\mathrm{MM}$ and $\mathrm{MB}$, respectively). There were no significant differences. In fact, the opposite trend was indicated-broods from Bl-F $\mathrm{F}_{1}$ fathers tended to be smaller, although not significantly so. My sample sizes are admittedly small, but if there were sufficient male embryo mortality to cause the 
TABLE 5

A summary of sex ratios of the nth broods produced by females in the backcrosses involving the strains $\mathrm{Ma}$ and $\mathrm{Bl} / \mathrm{Ir}$. N is the number of females from which data were taken. There was no significant difference among broods within backcrosses

$\begin{array}{cllll}\text { Brood No. } & \text { MM } & \text { MB } & \text { BM } & \text { BB } \\ 1 & 35: 45 & 40: 51 & 45: 45 & 62: 54 \\ & 0 \cdot 778 & 0 \cdot 784 & 1 \cdot 000 & 1 \cdot 148 \\ & N=16 & N=15 & N=14 & N=16 \\ 2 & 51: 90 & 67: 97 & 60: 53 & 93: 81 \\ & 0 \cdot 567 & 0 \cdot 691 & 1 \cdot 132 & 1 \cdot 148 \\ 3 & N=14 & N=14 & N=13 & N=16 \\ & 59: 93 & 71: 87 & 47: 62 & 86: 89 \\ & 0 \cdot 634 & 0 \cdot 816 & 0 \cdot 758 & 0 \cdot 966 \\ 4 & N=12 & N=12 & N=11 & N=15 \\ & & 24: 51 & & \\ & & 0 \cdot 471 & & \\ & & N=6 & & \end{array}$

observed sex ratios, a tendency toward lowered fecundity should have been observed.

A final consideration involves the effect of parity or female age on sex ratio, as suggested by the work of Trivers and Willard (1973). If guppies conform to their predictions, there should be a reduction in sex ratio with successive broods. Table 5 summarises the combined sex ratios for all first, second, and third broods (in one instance, fourth broods) from the four backcrosses. Although there appears to be much variation from brood to brood, there are no significant differences between even the most extreme sex ratios (e.g., MM broods 1 and $2, \mathrm{MB}$ broods 3 and $4, \mathrm{BM}$ broods 2 and 3). I conclude from these data that guppies do not follow the model of Trivers and Willard. Females do not influence the sex ratio of their offspring even though many females die before producing a third brood and there is an obvious decline in viability with increasing age.

\section{Discussion}

The above data show:

(1) that some inbred strains of guppies, Poecilia reticulata, have sex ratios $(\mathrm{M}: \mathrm{F})$ significantly less than unity;

(2) that the degree of sex ratio bias is correlated with approximate age of the strains;

(3) that the reduction in sex ratio is mediated by $Y$-linked genes;

(4) that the observed effects do not result from the differential survival of male and female embryos;

(5) that females do not influence the sex ratio of their broods.

The question now arises as to whether the observed sex ratio phenomenon is in some way adaptive, or if it merely represents a genetic condition facilitated by laboratory conditions and inbreeding.

First, it must be pointed out that sex ratios in nature are $1: 1$ at birth and that female-biased sex ratios, where they exist, are caused primarily by differential predation on the brightly coloured and continuously sexually 
active males (Haskins et al., 1961; Seghers, 1973; Farr, 1975; Endler, $1978,1980)$. There are thus no inherently higher costs of producing males than females which could cause a sex ratio bias (Fisher, 1930; Howe, 1977; Maynard Smith, 1978; Uyenoyama and Bengtsson, 1979). The cause of the bias must be found in differences between the laboratory and natural environments.

Perhaps the major difference between our laboratory stocks and natural populations of guppies is the degree of inbreeding. The oldest strains, e.g., Ma and Pa, are descendants of Schmidt's (1920) and Winge's (1922, 1927) original stocks, and if we assume a conservative generation time of three months, the older strains have been maintained in small laboratory populations for more than 200 generations. As most strains are monomorphic for male secondary sexual colouration, there is no opportunity for females to outbreed by selectively mating with males carrying rare or novel colour patterns (Farr, 1977, 1980). Effective population size is further reduced by intermale competition, and because dispersal capabilities are lacking, there is a high probability of matings between close relatives. Age of the strains should be correlated with the degree of inbreeding, so can inbreeding and local mate competition (Hamilton, 1967; Maynard Smith and Stenseth, 1978; Maynard Smith, 1978; Taylor and Bulmer, 1980; Colwell, 1981) have resulted in selection for reduction in the number of males?

Two factors speak against the possibility. First, mating in our populations is random, so the required mating structure for local mate competition does not exist. More importantly, however, classic haploid selection theory dictates that under no mating system will a $Y$-linked gene causing reduced $Y$-chromosome fitness be favoured. The sex ratio phenomenon cannot be explained by a conventional selection regime. I offer the following two alternative explanations.

The sex ratio bias could be a result of pleiotropic effects of $Y$-linked genes which confer superior competitive ability to males. The major factors influencing male reproductive success, i.e., secondary sexual colouration and rate of different sexual behaviour patterns, are primarily $Y$-linked (Haskins et al., 1961; Farr, 1980 and in prep.). Mutations which increase a male's sexual activity and also cause a reduction in proportion of males in his offspring could be established. If $s_{1}$ is the reduction in fitness of the new mutation because of the sex ratio effect, and $s_{2}$ is the gain in fitness because of increased ability to compete with normal males, the new mutation will spread as long as $s_{2}>s_{1}$ (fitnesses additive) or $s_{2} /\left(1+s_{2}\right)>s_{1}$ (fitnesses multiplicative).

The primary factor determining reproductive success in male guppies is the frequency at which they court females (Farr, 1980). A secondary factor is the frequency of rape attempts, and aggression is negatively correlated with reproductive success. There is no significant correlation between strain sex ratio and any of the quantitative behavioural traits characteristic of each strain (data from table 1 in Farr, 1980). However, if one compares sex ratios with overall ability of strains to compete with other strains, the correlation is significant (Spearman's $r_{s}=-0.78, \alpha<$ $0 \cdot 05)$. The more successful are males of a strain in competing for females, the lower is the sex ratio of that strain. It is therefore possible that $Y$-linked genes increasing the competitive ability of males also result in lower production or viability of $Y$-bearing sperm. 
A final possible cause of the sex ratio phenomenon could be the accumulation of deleterious alleles on the $Y$-chromosome through genetic drift (Nei, 1970) or the process known as Muller's ratchet (Charlesworth, 1978). Nei (1970) showed that in the absence of recombination, random drift can result in a more rapid accumulation of mutations on $Y$-chromosomes than on $X$-chromosomes. The effect is accelerated at small effective population sizes, but dampened if the mutations are not completely recessive, an unlikely condition (Charlesworth, 1978).

Charlesworth (1978) extended Muller's (1964) discussion of the advantages of recombination and sexual reproduction to an alternative theory of the evolution of inert $Y$-chromosomes. Basically, a population of asexual organisms can be divided into classes of individuals with $i$ harmful mutations per genome, with the lowest number of mutations in any individual being $j$. It is impossible for an individual with less than $j$ deleterious mutations to arise (reverse mutations are so rare as not to be significant factor), and there is always a chance that all individuals with $j$ deleterious mutations fail to reproduce because of sampling error. If this occurs, the smallest number of harmful mutations in any genome is at least $j+1$. Muller likened the phenomenon to a ratchet clicking around one notch every time the class with the lowest number of mutations is eliminated, and the rate at which the ratchet moves is inversely related to the size of the class with the lowest number of deleterious mutations (Maynard Smith, 1978). Because $Y$-chromosomes do not recombine with the $X$-chromosome, they are subject to the same disadvantages as asexual organisms with respect to the accumulation of harmful mutations. Both Nei and Charlesworth suggested that $Y$-chromosomes have accumulated a sufficient mutation load to be completely dysfunctional in most organisms.

The effective population sizes of our laboratory stocks are much lower than in nature, and there is no possibility of immigration of new genetic material from other populations. Guppies are unusual in that they carry functional $Y$-linked genes, and it is entirely possible that $Y$-chromosome deterioration through one of the above processes has affected the production or viability of $Y$-bearing sperm. Lloyd (1974) suggested that femaledominant sex ratios in several species of angiosperms are caused by the inferior competitive ability of male gametophytes as a result of the genetic erosion of $Y$-chromosomes. Although genes appear not to be expressed in animal spermatozoa (Muller and Settles, 1927; Lindsley and Lifschytz, 1972; Ford and Evans, 1973), delayed effects of events during spermatogenesis can result in differential competitive ability of sperm. Several relevant papers on mechanisms of segregation distortion and sperm competition can be found in Beatty and Gluecksohn-Waelsch (1972).

Of the two possible causes of the change in sex ratio in older guppy strains, the accumulation of deleterious alleles on the $Y$-chromosome is more likely than the pleiotropy hypothesis. There are populations in nature in which males are much more sexually active than any of our laboratory strains (Farr, 1975) without any effect on sex ratio. Any mutations which have arisen since establishment of the laboratory strains which simultaneously increase male competitive ability and decrease sex ratio should be countered by mutations which maintain the high competitive ability but restore the sex ratio to unity. There are no conditions peculiar to the laboratory which would allow one type of mutation and not the other. The 
reduction in effective population sizes, however, could greatly facilitate the genetic deterioration of the normally active $Y$-chromosome. The process is irreversible, and eventual extinction of the strains is not impossible.

Acknowledgements.-I thank A. Grafen and M. Ridley for an enlightening discussion of inbreeding and local mate competition. Dr J. Favor was a patient sounding board during development of this paper, and I thank him and Professor J. H. Schröder for comments on the manuscript. I am grateful to an anonymous reviewer for pointing out some key references. Ms. J. Byers provided typing and editorial assistance. The work was supported first by a postdoctoral fellowship from the Alexander von Humboldt Foundation, then by a grant from the Deutsche Forschungsgemeinschaft to Professor Schröder.

\section{REFERENCES}

AFFLECK, R. J. 1960. Notes on the breeding of the domesticated grey guppy Lebistes reticulatus (Peters). Proc. Zool. Soc. London, 135, 631-640.

BARTHOLOMEW, D. J. 1959. A test of homogeneity for ordered alternatives. Biometrika, 46, 36-48.

BEATTY, R. A., AND GLUECKSOHN-WAELSCH, S. 1972. Editors, Edinburgh Symposium on the Genetics of the Spermatozoon. Published by the editors, Edinburgh and New York.

CHARLESWORTH, B. 1978. Model for evolution of $Y$ chromosomes and dosage compensation. Proc. Natl, Acad. Sci. USA, 75, 5618-5622.

COLWELL, R. K. 1981. Group selection is implicated in the evolution of female-biased sex ratios. Nature, 290, 401-404.

DZWILlO, M. 1959. Genetische Untersuchungen an domestizierten Stämmen von Lebistes reticulatus (Peters). Mitt. Hamburg Zool. Mus. Inst., 57, 143-186.

ENDLER, J. A. 1978. A predator's view of animal color patterns. Evol. Biol., 11, 319-364.

ENDLER, J. A. 1980. Natural selection on color patterns in Poecilia reticulata. Evolution, 34, 76-91.

FARR, J. A. 1975. The role of predation in the evolution of social behavior of natural populations of the guppy, Poecilia reticulata (Pisces: Poeciliidae). Evolution, 29, 151-158.

FARR, J. A. 1977. Male rarity or novelty, female choice behavior, and sexual selection in the guppy, Poecilia reticulata Peters (Pisces: Poeciliidae). Evolution, 31, 162-168.

FARR, J. A. 1980. Social behavior patterns as determinants of reproductive success in the guppy, Poecilia reticulata Peters (Pisces: Poeciliidae)-An experimental study of the effects of intermale competition, female choice, and sexual selection. Behaviour, 74, 38-91.

FISHER, R. A. 1930. The Genetical Theory of Natural Selection. Dover, New York.

FORD, C. E., AND EVANS, E. P. 1973. Robertsonian translocations in mice: segregational irregularities in male heterozygotes and zygotic unbalance. Chromosomes Today, 4, 387-397.

HAMILTON, W. D. 1967. Extraordinary sex ratios. Science, 156, 477-488.

HASKinS, C. P., HASKinS, E. F., McLA UGHLin, J. J. A., AND HEWITT, R. E. 1961. Polymorphism and population structure in Lebistes reticulatus, an ecological study. In Vertebrate Speciation ed. W. F. Blair, pp. 320-395. Univ. Texas Press, Austin.

HASKINS, C. P., YOUNG, P., HEWITT, R. E., AND HASKINS, E. F. 1970. Stabilised heterozygosis of supergenes mediating certain $Y$-linked colour patterns in populations of Lebistes reticulatus. Heredity, 25, 575-589.

HOWE, H. F. 1977. Sex ratio adjustment in the common grackle. Science, 198, 744-746.

KRUMHOLZ, L. A. 1948. Reproduction in western mosquitofish, Gambusia affinis affinis (Baird and Girard). Ecol. Monog., 18, 1-43.

LINDSLEY, D. L., AND LIFSCHYTZ, E. 1972. The genetic control of spermatogenesis in Drosophila. In Edinburgh Symposium on the Genetics of the Spermatozoon, eds. R. A. Beatty and S. Gluecksohn-Waelsch, pp. 203-222. Published by the editors, Edinburgh and New York.

LLOYD, D. G. 1974. Female-predominant sex ratios in angiosperms. Heredity, 32, 35-44.

MAYNARD SMITH, J. 1978. The Evolution of Sex. Cambridge Univ. Press.

MAYNARD SMITH, J., AND STENSETH, N. C. 1978. On the evolutionary stability of the female-biased sex ratio in the wood lemming (Myopus schisticolor): the effect of inbreeding. Heredity, 41, 205-214. 
MULlER, H. J. 1964. The relation of recombination to mutational advance. Mutat. Res., 1, $2-9$.

MULLER, H. J., AND SETTLES, F. 1927. The non-functioning of the genes in spermatozoa. $Z$. indukt. Abstamm.-Vererblehre, 43, 285-312.

NEI, M. 1970. Accumulation of nonfunctional genes on sheltered chromosomes. Amer. Natur., 104, 311-321.

SCHMIDT, J. 1920. Racial investigations. IV. The genetic behavior of a secondary sexual chaiacter. C.R. Trav. Lab. Carlsberg, 14(8), 1-12.

SEGHERS, B. H. 1973. An analysis of geographic variation in the antipredator adaptations of the guppy, Poecilia reticulata. Ph.D. Thesis, Univ. British Columbia.

SNEDECOR, G. W., AND COCHRAN, W. G. 1967. Statistical Methods. Iowa State Univ. Press, Ames.

SOKAL, R. R., AND ROHLF, F. J. 1969. Biometry. Freeman, San Francisco.

TAYLOR, P. D., AND BULMER, M. G. 1980. Local mate competition and the sex ratio. J. Theor. Biol., 86, 409-419.

TRIVERS, R. L., AND WILLARD, D. E. 1973. Parental ability to vary the sex ratio of offspring. Science, 179, 90-92.

UYENOYAMA, M. K., AND BENGTSSON, B. O. 1979. Towards a genetic theory for the evolution of the sex ratio. Genetics, 93, 721-736.

WINGE, Ö. 1922. One-sided masculine and sex-linked inheritance in Lebistes reticulatus. J. Genet., 12, 145-162.

WINGE, Ö. 1923. Crossing-over between the $\mathrm{X}$ and $\mathrm{Y}$ chromosome in Lebistes. J. Genet., 13, 201-217.

WINGE, Ö. 1927. The location of eighteen genes in Lebistes reticulatus. J. Genet, 18, 1-42. WINGE, Ö. 1930. On the occurrence of XX males in Lebistes, with some remarks on Aida's so-called "nondisjunction" males in Aplocheilus. J. Genet., 23, 69-76.

WINGE, Ö. 1934. The experimental alteration of sex chromosomes and vice versa, as illustrated in Lebistes. C.R. Trav. Lab. Carlsberg Ser. Physiol., 21, 1-49.

WINGE, Ö., AND DITLEVSEN, E. 1938. A lethal gene in the Y-chromosome of Lebistes. C.R. Trav. Lab. Carlsberg. Ser. Physiol., 22, 203-210.

WINGE, Ö., AND DITLEVSEN, E. 1947. Colour inheritance and sex determination in Lebistes. Heredity, 1, 65-83.

WU, Y. C., HOY, J. B., AND ANDERSON, J. R. 1974. The relationship between length, weight, and brood size of the mosquitofish, Gambusia affinis (Baird and Girard) (Cyprinodontes: Poeciliidae). Calif. Vector Views, 21(7), 29-43.

YAMAMOTO, T. 1975. The medaka, Oryzias latipes, and the guppy, Lebistes reticularis (sic). In Handbook of Genetics, vol. 4 Ed. R. C. King, pp. 133-149. Plenum, New York. 